\title{
ANTIOXIDANT AND ANTIBACTERIAL ACTIVITIES OF FOUR UNDERUTILIZED FRUITS OF BANGLADESH
}

\author{
Ashiq Arafat Zitu, Jahid Hasan Shourove, \\ Mo Mozammel Hoque, Rowshon Ara* \\ Department of Food Engineering and Tea Technology, Shahjalal University of \\ Science and Technology, Sylhet, Bangladesh
}

Keywords: Underutilized fruits, Zone of inhibition, Antioxidant activity, Minimum inhibitory concentration, Minimum bactericidal concentration

\begin{abstract}
Antioxidant and antibacterial activities of four underutilized fruits namely Jujube (Ziziphus mauritiana Lam.), Olive (Elaeocarpus serratus L.), Roselle (Hibiscus sabdariffa L.), and Taikor (Garcinia pedunculata Roxb.) commonly found in Bangladesh were evaluated. The highest total phenolic content $(685.08 \pm 27.65$ $\mathrm{mg} \mathrm{GAE} / 100 \mathrm{ml})$ and total flavonoid content $(148.18 \pm 0.40 \mathrm{mg} \mathrm{QE} / 100 \mathrm{ml})$ were found in Taikor extract, which compliance with its highest DPPH scavenging activity and antibacterial properties. It exerted a significantly higher $(\mathrm{p} \leq 0.05)$ zone of inhibition against Escerichia coli, Staphylococcus spp. and Pseudomonas spp. than the other experimented fruit extracts. The antioxidant activity was found as Taikor $(43.15 \pm 1.61 \%)>$ Roselle $(33.07 \pm 1.61 \%)>$ Olive $(28.68 \pm 0.78 \%)>$ Jujube $(24.81 \pm 1.34 \%)$. Bacillus spp. are found to be more susceptible to the experimented sample extracts. Fruit samples studied may be utilized as potential sources of natural antioxidants and antibacterial compounds, and their extracts may be used as natural biopreservatives to extend the shelf life of foodstuffs.
\end{abstract}

\section{Introduction}

Underutilized fruits, potentially valuable resources to health and nutrition insecurity, are easier to grow and hardy in nature. They are rich sources of nutritional and medicinal values that have remarkable scope in different food and nutraceutical industries (Pal et al. 2019). The usage of various food additives, antioxidants, and antibacterial agents is rapidly increasing in Bangladesh. Application of synthetic compounds as food additives for various purposes affects public health including liver damages, carcinogenesis, and other toxicities (Kaur et al. 2020). Fruits and vegetables are natural sources of polyphenols and vitamins having antioxidant, antimicrobial, and anticarcinogenic properties (Koley et al. 2016). Nowadays, use of medicinal plants and fruit extracts having strong antibacterial and antioxidant potentials greatly increased (Shahbazi et al. 2016). Jujube (Ziziphus mauritiana) contains a good amount of compounds having antioxidant and antimicrobial properties (Afroz et al. 2014). In Bangladesh, about 12 varieties of jujubes are grown (Talukdar et al. 2014). Among them, the local sour variety is prevalent and commonly found all over the country. Olive (Elaeocarpus serratus) a tropical fruit is rich in flavonoids, condensed tannins, carotenoids, and Vitamin C (Fernando et al. 2019). Roselle (Hibiscus sabdariffa) is a fruit with dark red outer layer that gives it a distinct appearance. Utilization of its extract may include natural food colorants, emulsions for carbonated drinks, flavoring agents, and herbal medicine (Jung et al. 2013, Abdallah 2016). Taikor (Garcinia pedunculata) has a juicy interior with edible arils. Extract of this fruit has antioxidant, antimicrobial, anti-inflammatory, hepatoprotective, and cardioprotective properties (Mudoi et al. 2012, Islam et al. 2015). However, few studies have explored the antioxidants and antimicrobial properties of these four underutilized fruits. The knowledge regarding such fruits' antioxidant and

*Author for correspondence: <rowshonara-fet@sust.edu>. 
antibacterial properties is crucial for improving their application to the food and pharmaceutical industries and in contributing to the creation of new products. Thus in the present study was conducted to evaluate the antioxidant and antibacterial activity against Bacillus spp., Staphylococcus spp., Escherichia coli, Pseudomonas spp. of underutilized fruits such as Jujube, Olive, Roselle, and Taikor.

\section{Materials and Methods}

Fresh and matured Jujube (local sour variety), Olive, Roselle, and Taikor fruits were collected from Bandar Bazar, Sylhet, Bangladesh. Total phenolic content was measured using the FolinCiocalteu's colorimetric assay (Amorim et al. 2008). Total flavonoid contents (TFC) was determined using the aluminum chloride colorimetric method (Meda et al. 2005). DPPH radical scavenging activity was evaluated according to Brand-Williams et al. (1995). Antibacterial activity of fruit extracts was determined by the agar disc-diffusion method followed by Mayachiew and Devahastin (2008). Two gram Positive (Bacillus spp. and Staphylococcus spp.) and two Gram negative (Escherichia coli and Pseudomonas spp.) bacteria were collected from the laboratory of Department of Genetic Engineering and Biotechnology, Shahjalal University of Science and Technology, Sylhet, Bangladesh to investigate the potential activity of the extracts. Ciprofloxacin was used as the antibiotic for the blank test. The in vitro antibacterial property (Minimum Inhibitory Concentration and Minimum Bactericidal Concentration) of the samples was evaluated based on broth micro dilution test (Shahbazi et al. 2015). Methanol extracts were dissolved in Nutrient broth containing 5\% (v/v) DMSO to reach final concentrations of $10 \mathrm{mg} / \mathrm{ml}$. Next, selected dilutions were made in a concentration ranging between $1-10 \mathrm{mg} / \mathrm{ml}$. Minitab statistical software was used to analyze the variance by the Tukey test. The $\mathrm{p} \leq 0.05$ was regarded as statistically significant. Data were expressed as means \pm standard deviation (SD) of three independent measurements.

\section{Results and Discussion}

Total phenolic content (TPC) and total flavonoid content (TFC), as well as antioxidant activity of Jujube (Z. mauritiana), Olive (E. serratus), Roselle (H. sabdariffa), and Taikor ( $G$. pedunculata) are presented in Figs 1-3. Polyphenols are bio-metabolites and a critical key for determining the antioxidant capacity (Abdallah 2016, Fernando et al. 2019, Kaur et al. 2020). The TPC was found to be highest in Taikor extract $(685.08 \pm 27.65 \mathrm{mg} \mathrm{GAE} / 100 \mathrm{ml})$ and lowest in Jujube $(421.75 \pm 17.5 \mathrm{mg}$ GAE$/ 100 \mathrm{ml}$ ) (Fig. 1). Roselle had comparatively higher TPC $(539.25 \pm 16.39 \mathrm{mg} \mathrm{GAE} / 100 \mathrm{ml})$ than that of the Olive $(440.08 \pm 11.81 \mathrm{mg} \mathrm{GAE} / 100 \mathrm{ml})$.

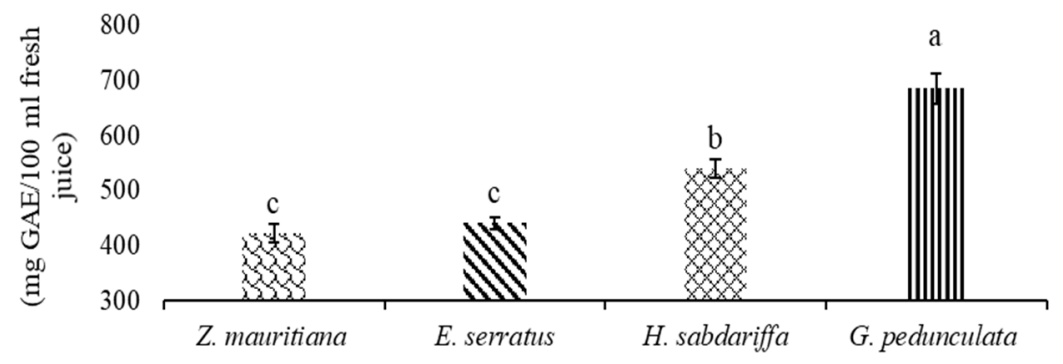

Fig. 1. Total phenolic content (TPC) Z. mauritiana, E. serratus, H. sabdariffa, and G. pedunculata. Values are given as mean \pm SD. Different letters $(\mathrm{a}-\mathrm{c})$ between the columns are significantly different (Tukey's test, $\mathrm{p} \leq 0.05)$. 
TPC of Bangladeshi native sour Jujube type is much higher than that of Indian Jujube and Bangladeshi Apple Kul variant (Afroz et al. 2014, Koley et al. 2016). These differences in the phenolic composition may depend on some factors such as variety, soil composition, climatic conditions, and light intensity (Krishna and Parashar 2013). Extraction procedure may also significantly influence the total phenolic content (Jiang et al. 2019).

Results presented in Fig. 2 showed that total flavonoid contents of the Taikor had a significantly $(\mathrm{p} \leq 0.05)$ higher amount of flavonoid $(148.18 \pm 0.40 \mathrm{mg} \mathrm{QE} / 100 \mathrm{ml})$ than the Roselle (118.87 $\pm 1.09 \mathrm{mg} \mathrm{QE} / 100 \mathrm{ml})$, Olive $(92.30 \pm 0.80 \mathrm{mg} \mathrm{QE} / 100 \mathrm{ml})$, and Jujube (90.19 \pm $0.30 \mathrm{mg} \mathrm{QE} / 100 \mathrm{ml})$. All the fruits were found to contain higher amounts of flavonoids than another underutilized fruit Carambola $(2.56 \pm 0.40 \mathrm{mg}$ QE/100 ml) as reported by Shourove et al. (2020). Mudoi et al. (2012) also reported that the methanolic extract of $G$. pedenculata had contained $71.4 \pm 0.84 \mathrm{mg} \mathrm{QE} / 100 \mathrm{~g}$ on dry weight basis. Fernando et al. (2019) found a significantly higher amount of flavonoids in Olive extract (120.49 QE mg/100 g). The higher amount of phenolic compounds in these fruits contributes to their antioxidant activity, nutritional value, and therapeutic benefits.

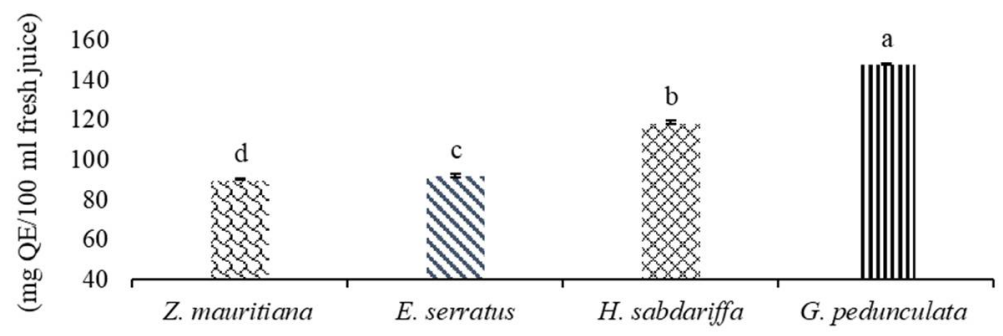

Fig. 2. Total flavonoid content (TFC) of Z. mauritiana, E. serratus, H. sabdariffa and G. pedunculata. Values are given as mean \pm SD. Different letters $(a-d)$ between the columns are significantly different (Tukey's test, $\mathrm{p} \leq 0.05)$.

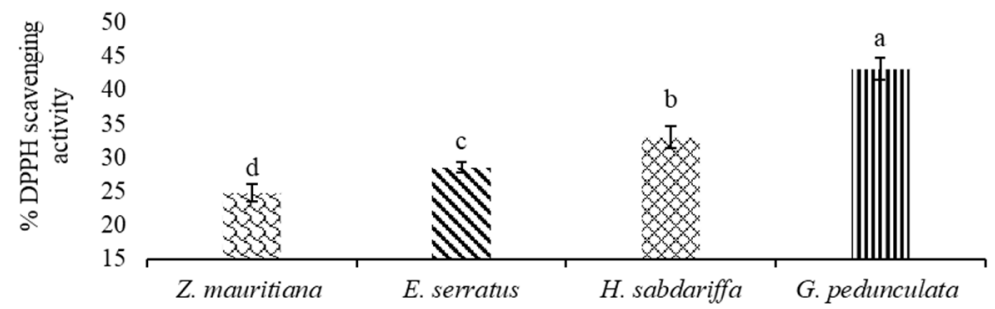

Fig. 3. DPPH radical scavenging activity of Z. mauritiana, E. serratus, H. sabdariffa and G. pedunculata. Values are given as mean \pm SD. Different letters $(a-d)$ between the columns are significantly different (Tukey's test, $\mathrm{p} \leq 0.05$ ).

Results of DPPH radical scavenging activity of four examined underutilized fruits are presented in Fig. 3 which revealed that the highest and lowest amount of DPPH radical scavenging activity was found in Taikor $(43.15 \pm 1.61 \%)$, and in Jujube $(24.81 \pm 1.34 \%)$, respectively. Taikor exhibited the highest DPPH free radical scavenging activity among all the tested samples supporting its TPC and TFC values. Jayaprakasha et al. (2006) reported that the DPPH scavenging activity of Taikor was $60 \pm 4.1$ and $67 \pm 5.1 \%$ for hexane and chloroform extract, respectively. 
Figure 4 showed the antibacterial activity of the samples that were tested. Maximum zone of inhibition $(17.33 \pm 1.52 \mathrm{~mm})$ was measured in case of methanolic extract of Taikor among all four fruit samples against the Gram-negative bacteria E. coli. The Gram-positive bacteria was found to be more sensitive than the Gram-negative bacteria. This might be due to the difference in their cell wall composition. A controversial result was found from the study of Beg et al. (2016), where the higher zone of inhibition of methanolic extract of Jujube was reported against E. coli. (ZOI= 11 $\mathrm{mm}$ ) than the $S$. aureus $(\mathrm{ZOI}=8 \mathrm{~mm})$.

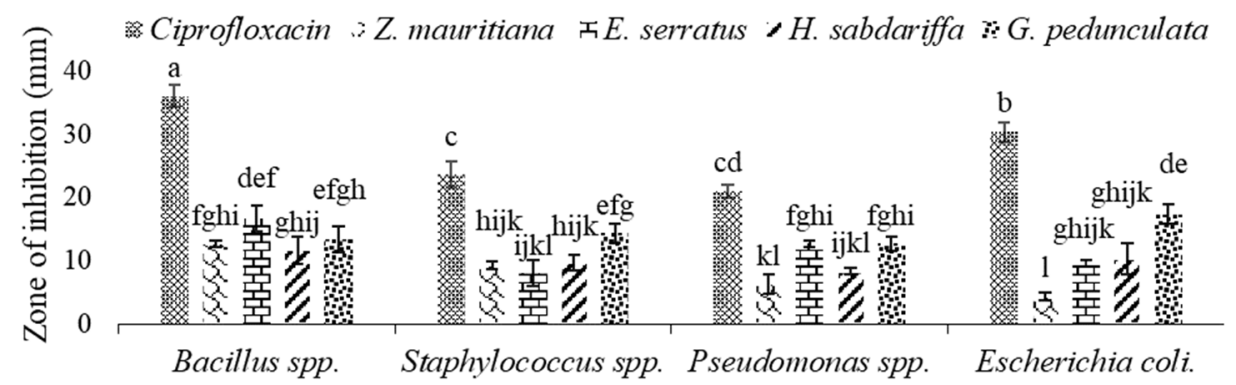

Fig. 4. Zone of inhibition of ciprofloxacin, Z. mauritiana, E. serratus, H. sabdariffa, and G. pedenculata extract against two Gram-positive and two Gram-negative bacteria. Values are given as mean \pm SD. Different letters $(\mathrm{a}-\mathrm{l})$ between the columns are significantly different (Tukey's test, $\mathrm{p} \leq 0.05$ ).

The highest inhibition zone was found in case of the methanolic extract of both Olive (ZOI= $16.67 \pm 2.08 \mathrm{~mm})$ and Roselle $(\mathrm{ZOI}=11.67 \pm 2.08 \mathrm{~mm})$ against Bacillus spp. The zone of inhibition was found by the Roselle extract against Bacillus spp. $(\mathrm{ZOI}=11.67 \pm 2.08 \mathrm{~mm})$, E. coli (ZOI=10.33 $\pm 2.51 \mathrm{~mm})$, S. aureus $(9.67 \pm 1.15 \mathrm{~mm})$, Pseudomonas spp. $(8.33 \pm 0.57 \mathrm{~mm})$. Jung et al. (2013) reported that ethanolic extract of Roselle showed the potent antimicrobial compound at $25 \mathrm{mg} / \mathrm{ml}$ concentration, where the zone of inhibition against $B$. subtilis $(10.70 \pm 0.87 \mathrm{~mm}), S$. aureus $(18.37 \pm 0.60 \mathrm{~mm})$ and $E$. coli $(11.73 \pm 0.61 \mathrm{~mm})$. Taikor has the maximum antibacterial property showing the highest inhibition zone in Gram-negative bacteria E. coli. The highest antibacterial activity $(36 \pm 1.73 \mathrm{~mm})$ of Ciprofloxacin was observed against Bacillus spp.while it was lowest $(21 \pm 1.00 \mathrm{~mm})$ against Pseudomonas spp.

Minimum Inhibitory Concentration (MIC) and Minimum Bactericidal Concentration (MBC) values are presented in Table 1. Sample extracts of different concentrations ranging from 1-10 $\mathrm{mg} / \mathrm{ml}$ were used to evaluate the MIC and MBC values. Taikor extract showed the highest antibacterial effect against all the experimented bacterial species at lower MIC $(6-8 \mathrm{mg} / \mathrm{ml})$ and MBC (7-9 mg/ml) values. The lowest MIC value $(5 \mathrm{mg} / \mathrm{ml})$ of the Olive extract was found against Gram-positive bacteria Bacillus spp. Roselle showed the highest antimicrobial effect against Staphylococcus spp., where MIC (8 mg/ml) and MBC (9 mg/ml). Fernando et al. (2019) reported that the ethanolic extract of Olive had the minimum inhibitory concentration against $E$. coli 1.3 $\mathrm{mg} / \mathrm{ml}$ and $S$. aureus $2.0 \mathrm{mg} / \mathrm{ml}$. Taikor extract had shown the highest TPC, TFC and antioxidant activity, which may be responsible for its higher antibacterial properties. Potential antimicrobial action of flavonoids is due to the complexation with the soluble extracellular proteins of the bacterial cell wall, which results in the breakage of the cell wall (Fernando et al. 2019). The differences in microorganism's susceptibility to antimicrobial agents may be attributed to the outer cytoplasmic membrane surrounding the thin peptidoglycan structure of Gram-negative bacteria (Lv et al. 2011). 
Table 1. Antibacterial effect of Z. mauritiana, E. serratus, H. sabdariffa, and G. pedunculata extracts indicated as Minimum Inhibitory Concentrations (MIC) and Minimum Bactericidal Concentrations (MBC) $\mathbf{m g} / \mathbf{m l}$.

\begin{tabular}{lccccccccc}
\hline \multirow{2}{*}{ Organisms } & \multicolumn{2}{l}{ Z. mauritiana } & E. serratus & \multicolumn{2}{l}{ H. sabdariffa } & \multicolumn{2}{l}{ G. pedunculata } \\
\cline { 2 - 9 } & $\begin{array}{l}\text { MIC } \\
(\mathrm{mg} / \mathrm{ml})\end{array}$ & $\begin{array}{l}\mathrm{MBC} \\
(\mathrm{mg} / \mathrm{ml})\end{array}$ & $\begin{array}{l}\mathrm{MIC} \\
(\mathrm{mg} / \mathrm{ml})\end{array}$ & $\begin{array}{l}\mathrm{MBC} \\
(\mathrm{mg} / \mathrm{ml})\end{array}$ & $\begin{array}{l}\mathrm{MIC} \\
(\mathrm{mg} / \mathrm{ml})\end{array}$ & $\begin{array}{l}\text { MBC } \\
(\mathrm{mg} / \mathrm{ml})\end{array}$ & $\begin{array}{l}\text { MIC } \\
(\mathrm{mg} / \mathrm{ml})\end{array}$ & $\begin{array}{l}\text { MBC } \\
(\mathrm{mg} / \mathrm{ml})\end{array}$ \\
\hline Bacillus spp. & 10 & NA & 5 & 6 & NA & NA & 7 & 8 \\
Staphylococcus spp. & NA & NA & 10 & NA & 8 & 9 & 6 & 7 \\
Pseudomonas spp. & NA & NA & 10 & NA & 10 & NA & 6 & 7 \\
Escherichia coli & NA & NA & 10 & NA & NA & NA & 8 & 9 \\
\hline
\end{tabular}

NA: No antibacterial activity was found with the concentrations used in this work.

The highest antioxidant and antimicrobial activity were found in Taikor among all the experimented fruit extracts. All of the fruit extracts are suggested as natural bio preservatives for extending the shelf life of stored food commodities and may be used in lieu of synthetic food additives in various food processing sectors. Further study is needed to optimize the antioxidant and antimicrobial activity of the sample extracts by using novel technology.

\section{Reference}

Abdallah EM 2016. Antibacterial activity of Hibiscus sabdariffa L. Calyces against hospital isolates of multidrug-resistant Acinetobacter baumannii. J. Acute Dis. 5(6): 512-516.

Afroz R, Tanvir EM, Islam MA, Alam F, Gan SH and Khalil MI 2014. Potential Antioxidant and antibacterial properties of a popular Jujube fruit: Apple Kul (Zizyphus mauritiana). J. Food Biochem. 38(6): 592-601.

Beg MA, Teotia U and Farooq S 2016. In vitro antibacterial and anticancer activity of Ziziphus. J. Med. Plants Stud. 4(5): 230-233.

Brand-Williams W, Cuvelier ME and Berset CLWT 1995. Use of a free radical method to evaluate antioxidant activity. LWT-Food Sci. Tech. 28(1): 25-30.

Fernando FDL, Caroline AB, Claudia ALC, Marta CTD and Eliana JS-A 2019. Evaluation of nutritional composition, bioactive compounds and antimicrobial activity of Elaeocarpus serratus fruit extract. Afr. J. Food Sci. 13(1): 30-37.

Islam M, Hoque M and Monalisa S 2015. Chemical composition, antioxidant capacities and storage stability of Citrus macroptera and Garcinia pedunculata fruits. Emir. J. Food Agric. 27(3): 275-282.

Jayaprakasha GK, Negi PS and Jena BS 2006. Antioxidative and antimutagenic activities of the extracts from the rinds of Garcinia pedunculata. Innov Food Sci. Emerg. Tech. 7(3): 246-250.

Jiang Z, Shi R, Chen H and Wang Y 2019. Ultrasonic microwave-assisted extraction coupled with macroporous resin chromatography for the purification of antioxidant phenolics from waste jackfruit (Artocarpus heterophyllus Lam.) peels. J. Food Sci. Tech. 56(8): 3877-3886.

Jung E, Kim Y and Joo N 2013. Physicochemical properties and antimicrobial activity of Roselle (Hibiscus sabdariffa L.). J. Sci. Food Agric. 93(15): 3769-3776.

Kaur N, Arora DS, Kalia N and Kaur M 2020. Antibiofilm, antiproliferative, antioxidant and antimutagenic activities of an endophytic fungus Aspergillus fumigatus from Moringa oleifera. Mol. Bio. Reports. 47(4): 2901-2911.

Koley TK, Kaur C, Nagal S, Walia S, Jaggi S and Sarika 2016. Antioxidant activity and phenolic content in genotypes of Indian jujube (Zizyphus mauritiana Lamk.). Arab. J. Chem. 9: 1044-1052. 
Krishna H and Parashar A 2013. Phytochemical constituents and antioxidant activities of some Indian Jujube (Ziziphus mauritiana Lamk.) Cultivars. J. Food Biochem. 13: 571-577.

Lv F, Liang H, Yuan Q and Li C 2011. In vitro antimicrobial effects and mechanism of action of selected plant essential oil combinations against four food-related microorganisms. Food Res. Int. 44(9): 30573064.

Mayachiew P and Devahastin S 2008. Antimicrobial and antioxidant activities of Indian gooseberry and galangal extracts. LWT - Food Sci. and Tech. 41(7): 1153-1159.

Meda A, Lamien CE, Romito M, Millogo J and Nacoulma OG 2005. Determination of the total phenolic, flavonoid and proline contents in Burkina Fasan honey, as well as their radical scavenging activity. Food Chem. 91(3): 571-577.

Mudoi T, Deka DC and Devi R 2012. In vitro antioxidant activity of Garcinia pedunculata, an indigenous fruit of North Eastern (NE) region of India. Int. J. PharmTech Res. 4(1): 334-342.

Pa IR, Abrol G, Singh AK, Punetha S, Sharma P and PandeyAK 2019. Nutritional and medicinal value of underutilized fruits. Acta Scien Agric. 3(1):16-22.

Shahbazi Y, Shavisi N, Karami N and Kakaei S 2015. Chemical composition and in vitro antibacterial activity of Ferulago angulata (Schlecht.) Boiss essential oil. Pharma Sci. 21(1): 6-11.

Shahbazi Y, Shavisi N and Mohebi E 2016. Effects of Ziziphora clinopodioides essential oil and nisin, both separately and in combination, to extend shelf life and control Escherichia colio157:H7 and Staphylococcus aureus in raw beef patty during refrigerated storage. J. Food Safety. 36(2): 227-236.

Shourove JH, Zzaman W, Hoque MM and Chowdhury RS 2020. Effect of thermal treatment on physicochemical stability and antioxidant properties of locally available underutilized star fruit juice. Asian Food Sci. J. 14(3): 41-53.

Talukdar MI, Rahman SS, Akhtaruzzaman M and Samad MA 2014. A comparative study on the nutritional quality of 5 (five) varieties of Bangladeshi jujubes (Zizyphus mauritiana). American J. Nutri and Food Sci. 1(2): 32-36.

(Manuscript received on 11 August, 2020; revised on 10 August, 2021) 